한국지 역사회생활 과학회 지 24(3) : 355 368, 2013

Korean J Community Living Sci 24(3) : 355 368, 2013

http://dx.doi.org/10.7856/kjcls.2013.24.3.355

$$
\begin{gathered}
\text { 아동의 성교육 경험, 성학대 인식, } \\
\text { 성지식 및 성의식에 관한 연구 } \\
\text { 최 영 희 } \\
\text { 수원대학교 아동가족복지학과 }
\end{gathered}
$$

\title{
A Study of Experience of Sex Education, Awareness of Sexual Abuse, Sex Knowledge, and Sexual Consciousness of Children
}

Choi, Young Hee"

Dept. of Child and Family Welfare, The University of Suwon, Hwaseong, Korea

\begin{abstract}
This research was performed for examining the differences of experience of sex education and the awareness of sexual abuse according to child's sex and economic background. Also the differences of sex knowledge and sexual consciousness were analyzed according to child's sex, economic background and sex education. Subjects were 425 children from two elementary schools and 10 community child centers in $\mathrm{H}$ city, Gyeonggi-do. The results were as follows. First, more girls thought the desirable place for sex education was home and more girls consulted sexual problems with their parents. Children from low economic backgrounds experienced sex education at school and community child centers rather than at home. Second, both boys and girls replied that sexual abuse was due to the attacker's fault but more girls than boys attributed the fault to themselves. Third, girls' sex knowledge grade was higher than boys. Fourth, boys showed a more open attitude toward heterosexual dating, and children with a low economic background showed a higher sex drive. Fifth, a high sex drive was related to low sexual knowledge, openness in dating and high sexual ethics.
\end{abstract}

Key words: sex education, sexual abuse, sex knowledge, sex consciousness

$\begin{array}{cl}\text { I. 서론 } & \text { 비율은 최근 들어 감소 추세를 보이고 있다. 보 } \\ & \text { 건복지부와 아동보호전문기관에서 발간한 아동 } \\ \text { 아동학대 사례들 중에서 성학대가 차지하는 } & \text { 학대현황보고서(Ministry of Health \& Welfare }\end{array}$

This research was supported by grants from Hwaseong-si Community Council of Social Welfare: Dept. of Child \& Adolescent.

접수일: 2013년 8월 8일 심사일: 2013년 8월 30일 게재확정일: 2013년 9월 16일

†Corresponding Author: Choi, Young Hee Tel: 82-31-220-2229

e-mail: heechoi@suwon.ac.kr

This is an Open-Access article distributed under the terms of the Creative Commons Attribution Non-Commercial License (http://creativecommons.org/licenses/by-nc/3.0) which permits unrestricted non-commercial use, distribution, and reproduction in any medium, provided the original work is properly cited. 
2011)에 따르면 2009년에 성학대 사례가 426 건 으로 $5.1 \%$ 를 차지했던 것을 기점으로 2010 년에 는 400건(4.7\%), 2011 년에는 368건(4.0\%)으로 감 소하였다. 성학대가 감소하는 것은 신체학대와 정서학대가 증가하고 있는 것과 비교되는 경향이 다. 아동 대상 성학대의 비율이 감소하고 있음은 한국성폭력상담소에서 발간하는 상담통계 자료 에서도 드러난다. 한국성폭력상담소에서 상담현 황을 조사한 2000년 이후로 계속 $12 \%$ 대를 차지 하던 아동(8 13세) 대상 성폭력상담 건수가 2010 년에는 $8.5 \%$ 로 낮아졌다가 2011년에는 $11.2 \%$, 2012 년에는 $10.9 \%$ 를 보이고 있어 감소 추세를 나타내고 있다. 이는 아동 성학대, 성폭력을 심각 한 범죄로 간주하고 그에 대한 처벌이 강화되는 과정에서 국민들이 아동들을 성학대와 성폭력으 로부터 보호하고자 하는 의식이 높아졌기 때문이 라고 사료된다.

아동복지법에 따르면, 성학대는 "아동에게 성 적 수치심을 주는 성희롱, 성폭행 등의 학대 행 위”로 규정하고 있다. 성학대를 경험한 후 아동 은 가해자에 대한 공포와 같은 불안증세가 두드 러지게 나타나고 수면장애를 보이기도 한다(Choi et al. 2009). 학령기 아동은 학업부진과 친구관계 의 곤란 뿐 아니라 부정적 신체상을 갖고 성에 대한 지식이 지나치며 우울과 불신감을 갖는다. 성폭력 피해를 경험한 12 15 세 아동을 조사한 $\operatorname{Shin(2011)ㅇㅡㄴ~ㅍㅣㅎㅐㅇㅏㄷㅗㅇ~ㄷㅐㅂㅜㅂㅜㄴㅇㅣ~ㄷㅏㅇㅑㅇㅎㅏㄴ~ㅅㅣㅁㄹㅣㅈㅓㄱ~}$ 증상을 경험하고 있음을 보고하였다. 피해아동들 은 가해자에 대한 분노 및 공포와 비참함, 슬픔 과 같은 고통스러운 감정을 경험하였고 수면과 섭식문제, 행동통제의 어려움을 경험하고 있었다.

성폭력 피해아동은 우울과 불신과 같은 증상 으로 고통을 받지만 그보다 더욱 심각한 것은 성 폭력의 장기적 영향이다. 아동기에 성 피해를 경 험한 사람들은 성인기까지 계속 수치심과 성적가 치에 대한 상실감, 그리고 자신이 그러한 역할에 동조했다는 죄책감을 경험한다(Lee \& Kim 2006). 이러한 심리적 후유증으로 인해 성피해를 경험한 사람들은 그렇지 않은 사람들에 비해 대인관계 능력과 대인 신뢰감, 문제해결력이 낮았다 $(\mathrm{Kim}$ \& Kim 2000). 또한 우울, 무력감, 낮은 자존감 등
의 문제와 감정조절, 특히 분노조절의 어려움을 경험하고 있었다(Oh 2003). 청소년 범죄로 인해 소년보호교육기관에 수용중인 여자 청소년들에 게서도 성피해를 입은 청소년은 비피해 청소년에 비해 우울과 불안을 높이 보이는 것으로 나타나 (Kwon 2002) 성피해는 그 어떤 문제보다 심리적 후유증을 깊게 남긴다는 것을 알 수 있다.

이와 같이 장, 단기적으로 부정적 영향이 막대 한 성학대, 성폭력 등의 피해의 영향을 차단하기 위해서는 무엇보다 예방이 필요하다. 아동 성학 대 예방교육에 관한 연구는 2000년 아동복지법을 개정하면서 아동학대 관련 조항이 신설되면서 본 격화되기 시작하였다. 그러나 이미 1996년에 유 아의 성학대 예방프로그램을 개발하여 실시한 연 구(Lee 1996)가 시행되어 성학대, 성폭력 예방교 육은 거의 20 년의 역사를 갖고 있다. 아동들 대 상의 성학대 예방교육은 주로 아동의 권리(Han 2003) 및 성학대에 대한 인식과 대처(Lee 1996; Ministry of Education 2008)에 초점을 두고 있다. 굿네이버스에서 아동들을 대상으로 아동권리를 중심으로 하는 성학대 예방교육(PAPCM)과 교육 과학기술부에서 전국의 초중등 학교에서 성에 관 한 지식과 태도 등의 폭넓은 교육의 한 부분으로 성학대를 다루고 있는 교육이 있다. 이러한 성학 대 예방교육은 아동 대상 성폭력을 감소시키는 데 기여하고 있을 것이나 그럼에도 불구하고 성 에 대한 가치관과 성문화가 변화하고 인터넷 사 용의 증가하면서 성 관련 범죄는 한시도 방심할 수 없는 상황이다.

또한 아동과 청소년이 경험하는 성 문제는 성인 으로부터의 성학대 뿐 아니라 아동과 청소년들 간 에서 발생하고 있는 성폭력도 간과할 수 없는 일 이다. 초등학생들을 대상으로 또래로부터 성폭력, 성희롱을 경험한 경험을 조사한 연구에서 피해를 경험한 아동이 33\%(Han 2007)에서 57\%(Choi 2004) 에 달하고 있었다. 약 $1 / 3$ 이상의 아동이 또래로부 터 성폭력 피해를 경험한 것이다. 그런데 이들 피 해 아동들의 $22 \%$ 정도는 일부러 무시하거나 모른 척 했다고 응답하였으며(Han 2007) $15 \%$ 정도의 아 동은 별 느낌이 없었다고 응답하였다(Choi 2004). 성폭력을 경험하고도 그것을 그저 장난이나 자연 
스러운 것으로 넘겨버리는 경우가 상당히 많다는 것을 의미한다. 이는 아동이 성장하여 성인이 되 었을 때 성폭력 행동을 하거나 당하는 것에 무감 각하여 성폭력이 행해질 수 있음을 시사한다. 그 러므로 아동과 청소년을 대상으로 올바른 성에 대 한 교육을 하는 것이 필요하다.

성교육은 어린 연령인 유아기부터 시작하는 것이 좋다. 특히 아동과 청소년기에 성문제가 관 심사로 대두되고 있으며 성학대의 피해를 가장 많이 입는 연령이 중학생 $(35.3 \%)$ 이며 다음이 초 등학교 고학년(27.7\%), 초등학교 저학년(15.5\%) 순이다(Ministry of Health \& Welfare 2011). 초등 학교 저학년에서부터 성학대가 급증하므로 초등 학교부터의 성교육은 매우 중요하다. 그러나 초 등학생을 대상으로 하는 성교육 내용은 성지식에 치우쳐 있고 효과적인 전달방법의 지침이 없어 아동들의 성교육 만족도는 매우 낮은 편이다 (Youn \& Kim 2001). 이에 교육과학기술부에서는 2008년에 초, 중, 고교생을 대상으로 하는 성교육 자료를 제작하였다. 초등학교, 중학교, 그리고 고 등학교급 별로 성교육의 목표와 교육 내용 및 지 도방법을 소개하고 있다. 초등학교 고학년에서는 이성교제, 성지식, 양성평등, 그리고 다양한 가족 유형 이해를 담고 있으며 중학교 1 학년에서는 성욕, 생명존중, 성폭력, 그리고 가정폭력에 대한 인식을 목표로 하고 있다.

이러한 내용들은 실제로 아동과 청소년의 성 행동과 상관이 있었다. 성교육을 받은 초등학생 은 성지식이 증가하였고 건전한 성태도가 증가하 였다(Kang 1994; Jang 1998; Hwang 1999). 비록 성교육의 내용과 방법에 아동들이 충분히 만족하 지 못하고 있지만(Kang 1994; Kim 1998) 성교육 의 효과가 있음은 부인할 수 없는 일이다. 심지 어 문란한 성태도를 보여 정신과 병동에 입원한 청소년들에게도 성교육 프로그램은 청소년의 성 의식과 성태도를 변화시키는 효과를 보이고 있었 다(Ryu et al. 2008).

성교육이 아동의 성의식 및 성태도에 긍정적 영향을 주었다는 대부분의 연구들은 실험연구를 통해 성교육의 효과를 보고하고 있다. 성교육을 실시하기 전과 후의 성의식 및 태도의 변화를 보
고하고 있다. 이러한 방법은 성교육의 효과를 검 증하기 위한 과학적이고 객관적인 방법이나 성교 육의 단기적 효과만을 측정한다고 볼 수 있다. 그러므로 성교육을 받았던 경험과 성교육을 통해 얻은 올바른 성지식 정도, 그리고 성의식의 관계 를 살펴본다면 성교육이 아동의 성지식과 성인식 과 관계가 있는지를 알 수 있을 것이다.

한편, 아동의 성에 대한 태도는 성에 따라 차 이가 있다. 남아가 여아보다 성 차별적인 인식이 높으며 성인식 수준은 낮았다(Hwang 1999; Han 2007). 여아가 남아에 비해 양성평등이나 성폭력 에 대한 이해가 높았다(Lee 2004). 남아가 성지식 에 대한 단편적인 지식은 높았으나 임신이나 피 임, 성윤리에 대해서는 $70 \%$ 의 아동이 잘 모른다 고 답하고 있어(Hwang 1999) 왜곡된 성지식에 노 출되어 있음을 알 수 있다. 왜곡된 성에 대한 지 식과 태도는 자칫 아동을 성폭력의 위험에 빠지 게 할 수 있는데, 위와 같이 남아가 여아에 비해 성차별적인 인식이 높고 성인식 수준이 낮으며 성에 대한 단편적 지식이 높다는 점, 그리고 또 래의 성폭력 가해경험 뿐 아니라 피해경험이 높 았다는 연구결과(Choi 2004; Han 2007)는 남아의 성에 대한 태도가 왜곡되어 있음을 간접적으로 나타내는 결과라 하겠다.

남아이든 여아이든 성폭력을 경험하면 사건 당시에는 가해자에 대한 분노와 공포, 비참함 등 의 감정을 경험하였고 사건 후에는 무력감과 행 동통제의 어려움을 경험하였다(Shin 2011). 이러 한 심리적, 행동적 고통을 야기하는 성폭력 대처 에 관한 방법과 능력은 부모의 지지와 상관이 있 었다(Yoo 2006). 특히 남아의 경우 부모의 지지 가 낮을 때 성폭력 피해에 대해 회피적 대처방식 이 높아 적절한 대처 능력이 떨어졌다. 부모의 지지는 아동의 성평등에 대한 인식과 성평등성과 관계가 있었으나 남아의 경우에는 성폭력 대처방 식과도 상관이 있어 부모의 지지가 남아의 경우 에 더 큰 영향을 미치고 있음을 알 수 있다.

부모의 지원과 지지는 성폭력 대처능력과 상 관이 있을 뿐 아니라 성폭력에 노출되는 위험성 과도 관련이 있다. 아동이 성학대에 노출되는 원 인으로 아동의 낮은 자존감이나 외적 통제감, 성 
에 대한 왜곡된 인식 등 아동의 개인적 요인 뿐 아니라 부모의 적절한 보호 부족과 방임과 같은 가족 관련 요인을 들 수 있다(Choi et al. 2009). 부모로부터 충분한 보호와 지지를 받지 못하는 아동은 성학대와 성폭력에 노출될 위험이 높을 것으로 보인다.

부모의 충분한 보호를 받지 못하는 아동이 부 모가 부재한 가정의 아동이라고 볼 수는 없다. 성학대 피해 아동에 국한된 조사는 발견하지 못 하여 전반적인 아동학대 피해아동의 조사 현황을 보면 친부모 가족의 아동은 2001 년에는 $25.5 \%$, 2009 년 에는 $28.1 \%$ 에서 2011 년에는 $32.8 \%$ 로 증 가한 반면 아동복지 시설 내의 학대 발생 사례는 2009 년에 6.3\%에서 2011 년에는 2.8\%로 감소하 였다(Ministry of Health \& Welfare 2011). 따라서 부모의 부재 자체보다는 빈곤한 가정환경이 아동 의 성학대와 성폭력에 위험요인이 될 수 있다는 지적이 있다. 빈곤 가정에서 아동학대가 많이 발 생한다(Lee \& Kim 2007; Kwak 2011)는 것은 일 반적으로 알려진 연구결과이다. 특별히 성학대에 관한 자료는 찾기 어려우나 빈곤 가정에서 아동 학대가 많이 발생한다는 점으로 미루어 성학대 역시 빈곤 가정에서 많이 발생할 것으로 사료된 다. 빈곤 가정에서 성학대가 많이 발생할 수 있 다는 것은 빈곤 자체보다는 부모의 충분한 보살 핌의 부족에 기인한다(Kwak 2011).

이상에서 살펴본 바, 아동 성학대를 예방하기 위해서는 성에 대한 올바른 지식과 성의식이 필 요하며 이를 위해 성교육이 필요함을 알 수 있 다. 이에 본 연구는 아동의 성교육 경험, 성학대 에 대한 인식, 성지식, 그리고 성의식에 대해 조 사하고자 하였다. 아동의 성지식과 성의식은 아 동의 성교육 경험 유무에 따라 차이가 있는가도 살펴보고자 하였다. 이러한 연구목적을 위해 다 음의 연구문제들을 제기하였다.

1. 아동의 성교육 경험은 아동의 성과 가정의 경제수준에 따라 차이가 있는가?

2. 아동의 성학대에 대한 인식은 아동의 성, 가정의 경제수준에 따라 차이가 있는가?

3. 아동의 성지식은 아동의 성과 가정의 경제 수준, 성교육 경험 유무에 따라 차이가 있는가?
4. 아동의 성의식은 아동의 성과 가정의 경제 수준, 성교육 경험 유무에 따라 차이가 있는가?

5. 아동의 성지식과 성의식은 어떠한 관계가 있는가?

\section{II. 연구방법}

\section{1. 연구대상}

본 연구는 성의식이 뚜렷해지는 시기인 초등 학교 고학년(5 6학년) 아동들의 성교육 경험, 성 학대에 대한 인식, 성지식, 성의식을 조사하기 위 하여 경기도 $\mathrm{H}$ 시에 거주하는 아동들을 대상으로 하였다. 조사하고자 하는 변인들이 부모의 보호 가 충분하지 못한 저소득층 가정의 아동들과 일 반아동들 간에 차이가 있는가를 알고자 하였다. 일반가정 아동들의 자료는 초등학교에서, 부모의 보호가 충분하지 못한 저소득층 가정 아동들의 자료는 지역아동센터에서 수집하였다. 경기도 $\mathrm{H}$ 시의 지역사회복지협의체에 소속된 지역아동센 터장 모임에서 본 연구에 참여하길 원하는 지역 아동센터 10 곳에서 초등학교 5, 6학년 아동들의 자료를 수집하였다. $\mathrm{H}$ 시 지역사회복지협의체 간 사가 질문지를 배부하고 회수하였다.

또한 경기도 $\mathrm{H}$ 시는 지역이 넓어 한 도시에 도 시와 농촌이 뚜렷이 구분되는 곳이다. $\mathrm{H}$ 시에 거 주하는 아동들의 성에 대해 파악하기 위해서 도 시와 농촌 지역을 골고루 조사하는 것이 타당하 다고 여겨 도시지역에 소재하는 초등학교 한 곳 과 농촌지역에 소재하는 초등학교 한 곳에서 초

Table 1. Demographic variables of subjects $(\mathrm{N}=425)$

\begin{tabular}{llrcc}
\hline & & $\mathrm{N}$ & $\%$ & Total \\
\hline \multirow{2}{*}{ Sex } & Boys & 207 & 48.8 & 425 \\
& Girls & 218 & 51.2 & $(100.0)$ \\
\hline \multirow{2}{*}{ Grade } & 5 & 343 & 80.7 & 425 \\
& 6 & 82 & 19.3 & $(100.0)$ \\
\hline Economic & Middle & 284 & 66.7 & 425 \\
background & Low & 141 & 33.3 & $(100.0)$ \\
\hline Residential & Urban area & 192 & 67.6 & 284 \\
area $^{2)}$ & Rural area & 92 & 32.4 & $(100.0)$ \\
\hline
\end{tabular}

\footnotetext{
1) Subjects of community child center

2) Exclude subjects of community child center
} 
등학교 5,6 학년 아동들을 대상으로 조사하였다. 초등학교 교장선생님께 본 연구의 취지를 설명하 고 연구에 동의하는 학교를 대상으로 하였다. $\mathrm{H}$ 시 지역사회복지협의체 간사가 학교를 방문하여 질문지를 배부하고 회수하였다.

연구대상 아동의 성, 학년, 경제적 배경 및 아 동의 거주지역은 Table 1 과 같다.

Table 1에서 보듯이 남아가 207 명(48.8\%), 여 아가 218 명(51.2\%)이었고 5학년이 343 명(80.7\%) 으로 대부분이었다. 일반아동이 284 명 $(66.7 \%)$, 지역아동센터를 이용하는 저소득 아동이 141 명 (33.3\%)이었다. 일반아동의 경우 도시지역 학교 아동이 192 명(67.6\%), 농촌지역 학교 아동이 92 명(32.4\%)이었다.

\section{2. 측정도구}

\section{1) 성교육}

아동의 성교육 경험에 대해 $\operatorname{Park}(2000)$ 의 연구 를 참조하여 5 문항을 질문하였다. (1) 성교육을 받아본 적이 있다면 어디에서 받았나, (2) 성교육 이 필요한 이유는 무엇이라고 생각하나, (3) 성교 육은 어디에서 하는 것이 좋다고 생각하나, (4) 성문제에 대한 상담은 누구와 하나, (5) 성에 대 한 지식은 어디에서 많이 얻고 있나의 5 문항이 며 5지선다형으로 질문하였다. 5지선다 항목들은 Table 2에 제시되어 있다.

\section{2) 성학대에 대한 인식}

성학대에 대한 인식은 $\mathrm{Ahn}(1996)$ 이 10 문항으 로 성학대 발생 후 대책에 대한 아동의 지각을 조사한 것을 참조하여 5 문항을 선택하였다. 선택 과정에서 아동복지기관 종사자들과 협의하여 정 하였다. (1) 누군가 나에게 성학대를 한다면 왜일 까, (2) 성학대를 당했을 때 제일 먼저 누구에게 말할까, (3) 혹시 성학대 당한 것을 부모님께 말 할 수 없다면 왜일까, (4) 성학대는 누구의 잘못 일까, (5) 성학대를 저지른 사람은 어떻게 해야할 까의 5 문항이며 4 지선다형으로 질문하였다. 4 지 선다 항목들은 Table 3 에 제시되어 있다.

\section{3) 성지식}

아동이 성에 대해 올바른 지식을 갖고 있는가 를 알기 위해 성지식에 관해 5 문항을 질문하였 다. Park(2000), Yoon(2004), Lee(2004)의 연구들에 공통적으로 포함되어 있는 문항들을 선택하였으 며, 선택한 문항들을 아동복지기관 종사자들과 함께 검토하고 표현을 수정하여 사용하였다. 예 를 들어 '여자가 임신하면 어떤 일이 일어나나 요?'를 ‘여자가 임신하면 나타나는 가장 뚜렷한 변화는 무엇인가요?’로 변경하였다. (1) 여자가 임신을 하면 나타나는 가장 뚜렷한 변화는 무엇 인가, (2) 성숙한 여자의 몸에서 한 달에 한 번씩 난자가 나오는 현상은 무엇인가, (3) 월경이란 무 엇인가, (4) 몽정이란 무엇인가, (5) 자위행위란 무엇인가의 5 문항이며 4지선다형으로 질문하여 정답 점수로 성지식의 정도를 측정하였다.

\section{4) 성의식}

성의식이란 성에 대한 관념이나 태도를 일컫 는 말로 성행위에 영향을 미치는 정신적 상태 (Ryu et al. 2008)이며, 본 연구에서는 성의식을 성역할정체감, 이성교제, 성충동, 그리고 성윤리 의 네 영역으로 조사하였다. Kang(1994), Hwang (1999), Park(2000)의 연구에서 공통적으로 사용된 문항들을 사용하였고, 성역할정체감 5 문항, 이성 교제 3 문항, 성충동 11 문항, 그리고 성윤리 11 문항이며 4점 척도로 조사하였다. 성역할정체감 은 '남자와 여자가 하는 일이 따로 있다'와 같이 양성평등 관련 문항들이며 점수가 높을수록 양성 평등 의식 정도가 높은 것이다. 이성교제는 '이 성친구를 사귀게 되면 부모님께 소개할 수 있다, 와 같이 이성교제에 대한 개방적인 정도를 질문 하고 있으며 점수가 높을수록 개방적인 태도가 높음을 의미한다. 성충동은 'TV나 비디오의 야한 장면을 보면 자꾸 보고 싶다'와 같이 성충동이 일어나는 정도를 질문하고 있으며 점수가 높을수 록 성충동 경험이 높은 것이다. 성윤리는 '성이 란 것은 고귀하고 순결한 것이다’와 같이 성윤리 를 갖는 정도를 질문하고 있으며 점수가 높을수 록 엄격한 성윤리를 갖고 있는 것이다. 성의식 측정도구의 신뢰도인 cronbach's $\alpha$ 는 .55로 높지 
Table 2. Experience of sex education $(\mathrm{N}=425)$

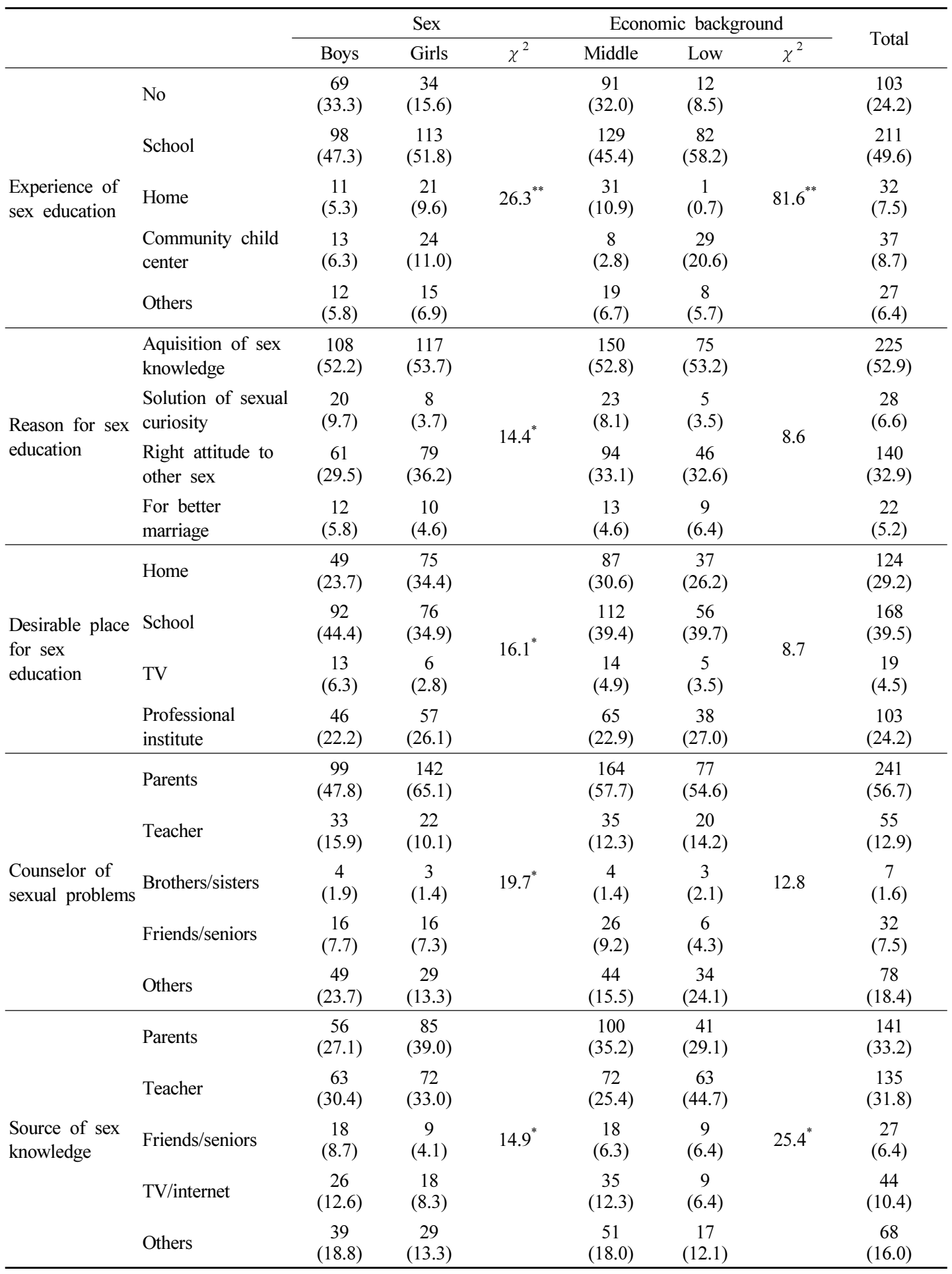

$* \mathrm{p}<.05, * * \mathrm{p}<.01$ 
Table 3. Differences of awareness of sexual abuse $(\mathrm{N}=425)$

\begin{tabular}{|c|c|c|c|c|c|c|c|c|}
\hline & & \multicolumn{3}{|c|}{ Sex } & \multicolumn{3}{|c|}{ Economic background } & \multirow{2}{*}{ Total } \\
\hline & & Boys & Girls & $\chi^{2}$ & Middle & Low & $\chi^{2}$ & \\
\hline \multirow{4}{*}{$\begin{array}{l}\text { Why someone would } \\
\text { abuse me sexually? }\end{array}$} & $\begin{array}{l}\text { Because he(she) likes } \\
\text { me }\end{array}$ & $\begin{array}{c}11 \\
(5.3)\end{array}$ & $\begin{array}{c}5 \\
(2.3)\end{array}$ & \multirow{4}{*}{$14.0^{*}$} & $\begin{array}{c}11 \\
(3.9)\end{array}$ & $\begin{array}{c}5 \\
(3.5)\end{array}$ & \multirow{4}{*}{4.5} & $\begin{array}{c}16 \\
(3.8)\end{array}$ \\
\hline & $\begin{array}{l}\text { Because of my short } \\
\text { skirt }\end{array}$ & $\begin{array}{c}3 \\
(1.4)\end{array}$ & $\begin{array}{c}15 \\
(6.9)\end{array}$ & & $\begin{array}{l}10 \\
(3.5)\end{array}$ & $\begin{array}{c}8 \\
(5.7)\end{array}$ & & $\begin{array}{c}18 \\
(4.2)\end{array}$ \\
\hline & $\begin{array}{l}\text { Because of my weak } \\
\text { appearance }\end{array}$ & $\begin{array}{c}56 \\
(27.1)\end{array}$ & $\begin{array}{c}52 \\
(23.9)\end{array}$ & & $\begin{array}{c}74 \\
(26.1)\end{array}$ & $\begin{array}{c}34 \\
(24.1)\end{array}$ & & $\begin{array}{c}108 \\
(25.4)\end{array}$ \\
\hline & Because he(she) is bad & $\begin{array}{c}132 \\
(63.8)\end{array}$ & $\begin{array}{c}140 \\
(64.2)\end{array}$ & & $\begin{array}{l}181 \\
(63.7)\end{array}$ & $\begin{array}{c}91 \\
(64.5)\end{array}$ & & $\begin{array}{c}272 \\
(64.0)\end{array}$ \\
\hline \multirow{4}{*}{$\begin{array}{l}\text { Whom would you first } \\
\text { tell about sexual } \\
\text { abuse? }\end{array}$} & Parents & $\begin{array}{c}160 \\
(77.3)\end{array}$ & $\begin{array}{c}179 \\
(82.1)\end{array}$ & \multirow{4}{*}{8.4} & $\begin{array}{c}226 \\
(79.6)\end{array}$ & $\begin{array}{c}113 \\
(80.1)\end{array}$ & \multirow{4}{*}{5.5} & $\begin{array}{c}339 \\
(79.8)\end{array}$ \\
\hline & Brothers/sisters & $\begin{array}{c}7 \\
(3.4)\end{array}$ & $\begin{array}{c}5 \\
(2.3)\end{array}$ & & $\begin{array}{c}8 \\
(2.8)\end{array}$ & $\begin{array}{c}4 \\
(2.8)\end{array}$ & & $\begin{array}{c}12 \\
(2.8)\end{array}$ \\
\hline & Best friend & $\begin{array}{c}4 \\
(1.9)\end{array}$ & $\begin{array}{c}8 \\
(3.7)\end{array}$ & & $\begin{array}{c}5 \\
(1.8)\end{array}$ & $\begin{array}{c}7 \\
(5.0)\end{array}$ & & $\begin{array}{c}12 \\
(2.8)\end{array}$ \\
\hline & Teacher & $\begin{array}{c}31 \\
(15.0)\end{array}$ & $\begin{array}{c}19 \\
(8.7)\end{array}$ & & $\begin{array}{c}36 \\
(12.7)\end{array}$ & $\begin{array}{c}14 \\
(9.9)\end{array}$ & & $\begin{array}{c}50 \\
(11.8)\end{array}$ \\
\hline \multirow{4}{*}{$\begin{array}{l}\text { Why would you not } \\
\text { tell sexual abuse to } \\
\text { parents first? }\end{array}$} & $\begin{array}{l}\text { Because he(she) threat } \\
\text { me }\end{array}$ & $\begin{array}{c}70 \\
(33.8)\end{array}$ & $\begin{array}{c}76 \\
(34.9)\end{array}$ & \multirow{4}{*}{12.1} & $\begin{array}{c}93 \\
(32.7)\end{array}$ & $\begin{array}{c}53 \\
(37.6)\end{array}$ & \multirow{4}{*}{9.2} & $\begin{array}{c}146 \\
(34.4)\end{array}$ \\
\hline & $\begin{array}{l}\text { Because of parents' } \\
\text { worries }\end{array}$ & $\begin{array}{c}80 \\
(38.6)\end{array}$ & $\begin{array}{c}80 \\
(36.7)\end{array}$ & & $\begin{array}{c}114 \\
(40.1)\end{array}$ & $\begin{array}{c}46 \\
(32.6)\end{array}$ & & $\begin{array}{c}160 \\
(37.6)\end{array}$ \\
\hline & $\begin{array}{l}\text { Because of parents' } \\
\text { scolding }\end{array}$ & $\begin{array}{c}17 \\
(8.2)\end{array}$ & $\begin{array}{c}4 \\
(1.8)\end{array}$ & & $\begin{array}{c}14 \\
(4.9)\end{array}$ & $\begin{array}{c}7 \\
(5.0)\end{array}$ & & $\begin{array}{c}21 \\
(4.9)\end{array}$ \\
\hline & Because of shame & $\begin{array}{c}32 \\
(15.5)\end{array}$ & $\begin{array}{c}46 \\
(21.1)\end{array}$ & & $\begin{array}{c}50 \\
(17.6)\end{array}$ & $\begin{array}{c}28 \\
(19.9)\end{array}$ & & $\begin{array}{c}78 \\
(18.4)\end{array}$ \\
\hline \multirow{4}{*}{$\begin{array}{l}\text { Sexual abuse is whose } \\
\text { fault? }\end{array}$} & $\mathrm{Me}$ & $\begin{array}{c}6 \\
(2.9)\end{array}$ & $\begin{array}{c}15 \\
(6.9)\end{array}$ & \multirow{4}{*}{6.6} & $\begin{array}{c}12 \\
(4.2)\end{array}$ & $\begin{array}{c}9 \\
(6.4)\end{array}$ & \multirow{4}{*}{8.0} & $\begin{array}{c}21 \\
(4.9)\end{array}$ \\
\hline & Parents & $\begin{array}{c}2 \\
(1.0)\end{array}$ & $\begin{array}{c}0 \\
(0)\end{array}$ & & $\begin{array}{c}1 \\
(0.4)\end{array}$ & $\begin{array}{c}1 \\
(0.7)\end{array}$ & & $\begin{array}{c}2 \\
(0.5)\end{array}$ \\
\hline & $\mathrm{He}$ (she) & $\begin{array}{c}179 \\
(86.5)\end{array}$ & $\begin{array}{c}183 \\
(83.9)\end{array}$ & & $\begin{array}{c}249 \\
(87.7)\end{array}$ & $\begin{array}{c}113 \\
(80.1)\end{array}$ & & $\begin{array}{c}362 \\
(85.2)\end{array}$ \\
\hline & Nobody's fault & $\begin{array}{c}18 \\
(8.7)\end{array}$ & $\begin{array}{c}19 \\
(8.7)\end{array}$ & & $\begin{array}{c}21 \\
(7.4)\end{array}$ & $\begin{array}{c}16 \\
(11.3)\end{array}$ & & $\begin{array}{c}37 \\
(8.7)\end{array}$ \\
\hline \multirow{4}{*}{$\begin{array}{l}\text { What should be done } \\
\text { to the sexual abuser? }\end{array}$} & To the prison & $\begin{array}{c}176 \\
(85.0)\end{array}$ & $\begin{array}{c}177 \\
(81.2)\end{array}$ & \multirow{4}{*}{6.6} & $\begin{array}{c}231 \\
(81.3)\end{array}$ & $\begin{array}{c}122 \\
(86.5)\end{array}$ & \multirow{4}{*}{4.0} & $\begin{array}{c}353 \\
(83.1)\end{array}$ \\
\hline & Pardon him(her) & $\begin{array}{c}3 \\
(1.4)\end{array}$ & $\begin{array}{c}5 \\
(2.3)\end{array}$ & & $\begin{array}{c}6 \\
(2.1)\end{array}$ & $\begin{array}{c}2 \\
(1.4)\end{array}$ & & $\begin{array}{c}8 \\
(1.9)\end{array}$ \\
\hline & Constantly watching & $\begin{array}{c}10 \\
(4.8)\end{array}$ & $\begin{array}{c}18 \\
(8.3)\end{array}$ & & $\begin{array}{l}23 \\
(8.1)\end{array}$ & $\begin{array}{c}5 \\
(3.5)\end{array}$ & & $\begin{array}{c}28 \\
(6.6)\end{array}$ \\
\hline & Don’t know & $\begin{array}{c}15 \\
(7.2)\end{array}$ & $\begin{array}{c}17 \\
(7.8)\end{array}$ & & $\begin{array}{c}21 \\
(7.4)\end{array}$ & $\begin{array}{c}11 \\
(7.8)\end{array}$ & & $\begin{array}{c}32 \\
(7.5)\end{array}$ \\
\hline
\end{tabular}

${ }^{*} \mathrm{p}<.05$ 
않은 편이었다.

\section{3. 자료분석}

아동의 성교육경험과 아동학대에 대한 인식이 배경변인에 따라 차이가 있는가를 분석하기 위하 여 chi-square 검증을 하였으며, 아동의 성지식과 성의식 정도가 배경변인에 따라 차이가 있는가는 t검증을 하였고, 성지식과 성의식과의 관계는 Pearson의 적률상관분석을 적용하였다.

\section{III. 결과 및 고찰}

\section{1. 아동의 성교육 경험}

연구대상 아동들의 성교육 경험이 아동의 성 과 가정의 경제적 수준에 따라 어떤 차이가 있는 가를 분석한 결과는 Table 2와 같다.

Table 2 를 보면 성교육을 받은 경험이 없는 아 동이 $24.2 \%$ 가 되어 약 $1 / 4$ 의 아동이 성교육 경험 이 없는 것으로 나타났다. 성교육 경험이 있는 경우에 대부분은 학교에서 교육을 받았으나 지역 아동센터와 가정에서 교육을 받은 경험이 있는 아동도 많았다. 성교육이 필요한 이유에 대해서 는 성에 대한 지식을 습득하기 위해서라는 응답 이 가장 많았으며(52.9\%) 다음이 이성에 대해 올 바른 태도를 갖기 위함 $(32.9 \%)$ 이라고 하였다. 바 람직한 성교육 장소로는 학교라고 응답한 아동이 $39.5 \%$ 로 가장 많았으며 다음이 가정(29.2\%), 전 문교육기관(24.2\%)이었다. 성 문제에 대해 누구 와 상담하는가에 대해서는 부모라고 응답한 아동 이 $56.7 \%$ 로 가장 많았다. 학교 선생님은 $12.9 \%$ 로 나타나 선생님과 상담하는 아동은 많지 않았다. 성지식의 출처에 대해서는 부모(33.2\%)와 선생님 (31.8\%)이라고 응답한 아동이 많았다. TV나 인터 넷이라고 응답한 아동도 $10.4 \%$ 가 되었다.

이들의 응답이 아동의 성에 따라 차이가 있는 가를 chi-square 검증한 결과, 아동의 성에 따른 차이가 뚜렷하였다. 남아가 여아에 비해 성교육 이 성에 대한 호기심을 해소하기 위한 것이라고 응답한 아동이 많았다 $\left(\chi^{2}=14.4, \mathrm{p}<.05\right)$. 남아와 여아 모두 성교육이 성에 대한 지식을 습득하고
이성에 대한 바른 태도를 갖기 위함이라고 응답 한 경우가 많았으나 남아는 성에 대한 호기심 해 소라고 응답한 아동이 여아보다 많아 남아의 성 호기심이 큼을 알 수 있었다. 이러한 결과는 $\operatorname{Park}(2000)$ 의 연구결과와 같아, 남아는 성에 대한 호기심이 크고 성교육이 성에 대한 호기심을 해 소시켜주고 있음을 알 수 있다.

성교육 장소로 바람직한 곳을 남아는 학교라 고 응답한 경우가 많은데 비해 여아는 가정이라 고 응답한 경우가 많았다 $\left(\chi^{2}=16.1, \mathrm{p}<.05\right)$. 성문 제를 상담하는 대상이 누구인가에 대해 여아는 부모라고 응답한 경우가 높았으며 남아는 선생님 이라고 응답한 경우가 여아보다 조금 더 높았다 $\left(\chi^{2}=19.7, \mathrm{p}<.05\right)$. 특히 남아는 부모나 선생님, 형 제자매 이외에 기타라고 응답한 경우도 많았다. 이를 보면 성에 관해 여아는 가정에서 부모로부 터 교육과 상담을 받고 싶어 하나 남아는 부모보 다는 학교와 선생님에게 의존하는 비율이 조금 더 높은 것을 알 수 있다. 성지식을 어디에서 얻 는가에 대해서도 여아는 부모님으로부터 얻는다 는 응답이 남아에 비해 높은 반면 남아는 친구나 선배, TV나 인터넷이라고 응답한 비율이 여아에 비해 높았다 $\left(\chi^{2}=14.9\right)$. Yoon(2004)도 여아는 부모 님으로부터, 남아는 컴퓨터에서 성에 대한 정보 를 주로 얻는다고 하였으며, $\operatorname{Kim}(2002)$ 의 연구에 서는 가정에서 부모가 여아에게 더 열심히 성에 대해 가르쳐준다고 하여 여아가 남아에 비해 성 지식 습득이나 성문제 상담을 부모를 통해 얻는 다는 것은 일반적인 경향으로 보인다.

가정의 경제적 수준에 따른 차이는 성교육을 받은 경험과 성지식의 출처에서 나타났다. 지역 아동센터를 이용하는 저소득 가정 아동은 학교와 지역아동센터에서 성교육을 받은 경험이 일반가 정 아동들에 비해 높았다. 일반가정의 아동들은 성에 대한 교육을 부모님에게 받는 경우가 가장 많은데 비해 저소득 가정의 아동들은 학교와 지역 아동센터 선생님으로부터 얻는 경우가 많았다. 이 는 저소득 가정의 경우에 학교와 지역아동센터를 통한 성교육이 더욱 중요하다는 것을 시사한다. 


\section{2. 성학대에 대한 인식}

다음으로 아동이 성학대에 대해 어떠한 인식 을 갖고 있는가를 아동의 성과 가정의 경제적 수 준에 따라 차이를 분석한 결과는 Table 3 와 같다.

Table 3을 보면 아동은 성학대를 당하는 이유 는 '그 사람이 이상해서’라는 응답을 가장 많이 하고 있으나(64.0\%) '자기가 어리고 약해보여서' 라고 생각하는 아동도 $25.4 \%$ 나 있음을 알 수 있 다. 이러한 응답은 성학대가 온전히 가해자의 잘 못이 아니라 자신의 나약함이 기여했다고 생각하 고 있음을 의미하고 이는 자신의 탓도 있다고 보 는 측면이 있음을 나타낸다. 성학대의 원인을 자 신에게 돌리는 경향은 아동이 어릴수록 크다고 볼 수 있는데, 유치원 아동과 초등학교 3학년 아 동들을 대상으로 1996년에 조사한 Ahn(1996)의 연구에서 성학대는 자신이 어리고 약해보여서라 고 응답한 아동이 가해자가 이상한 사람이어서라 고 응답한 아동보다 많았다. Ahn(1996)의 연구와 달리 본 연구에서 성학대의 원인을 자신에게 돌 리기보다 가해자의 탓으로 보는 것은 이처럼 아 동의 연령이 높은 것에 기인한 것도 있겠으나 그 보다는 성학대 예방교육이 널리 이루어졌기 때문 이라 사료된다. 성학대 예방교육이 10여년 전부 터 활발히 이루어져오면서 아동들이 성학대는 자 신의 탓이 아니라 가해자가 이상하고 나쁜 사람 이어서라는 인식을 갖게 된 것으로 보인다.

아동은 성학대를 당한다면 제일 먼저 부모에 게 말한다는 아동이 $79.8 \%$ 로 대부분을 차지하고 있었고 선생님이라고 응답한 아동들이 $11.8 \%$ 있 었다. 성학대를 당한 것을 부모님께 말할 수 없다 면 그 이유는 '부모님이 걱정하실까봐’(37.6\%)와 '그 사람이 겁을 주어서'(34.4\%)라는 응답이 대부 분이었다. '부끄러워서, 말하지 못할 것이라고 응 답한 아동도 $18.4 \%$ 있었다. 성학대는 대부분이 가해자 잘못이라고 알고 있으며(85.2\%) 가해자는 감옥에 보내야 한다(83.1\%)고 알고 있었다.

이러한 성학대에 대한 인식이 아동의 성과 가 정의 경제적 수준에 따라 어떠한 차이가 있는가 를 chi-square 검증한 결과 아동의 성에 따른 차 이만 나타났다 $\left(\chi^{2}=14.0\right)$. 남아와 여아 모두 '그 사람이 이상해서'라는 응답과 '내가 여리고 약해
보여서’라는 응답이 가장 많았으나 남아가 여아 보다 '가해자가 자기를 좋아해서' 성학대한다고 응답한 비율이 높았으며 여아는 남아보다 '자기 가 짧은 옷을 입어서, 그렇다고 응답한 비율이 높았다. 이는 성학대가 자신의 잘못이라고 생각 하는 경우가 여아가 남아보다 많음을 의미한다고 볼 수 있다. 이러한 경향은 초등학교 3학년 아동 을 조사한 Ahn(1996)의 연구에서도 마찬가지로 나 타나 여아가 성학대의 원인을 자기에게 있다고 인 식할 가능성이 남아에 비해 더 높음을 시사한다.

\section{3. 아동의 성지식}

다음으로 아동의 성에 대한 지식정도가 아동 의 성과 가정의 경제적 수준, 그리고 아동이 성 교육을 받은 경험 유무에 따라 차이가 있는가를 분석하여 그 결과를 Table 4 에 제시하였다.

Table 4. Differences of sex knowledge $(\mathrm{N}=425)$

\begin{tabular}{llccc}
\hline & & $\mathrm{M}$ & $\mathrm{SD}$ & $\mathrm{t}$ \\
\hline \multirow{2}{*}{ Sex } & Boys & 1.41 & 1.35 & $-3.04 * *$ \\
& Girls & 1.81 & 1.37 & \\
\hline Economic & Middle & 1.64 & 1.38 & \multirow{2}{*}{.62 } \\
background & Low & 1.55 & 1.37 & \\
\hline Experience of & Yes & 1.73 & 1.38 & \multirow{2}{*}{ sex education } \\
No & 1.22 & 1.27 & \\
\hline$* * \mathrm{p}<.01$ & & & & \\
\end{tabular}

Table 4에서와 같이 아동들의 성지식 점수는 5 점 만점에 평균 1.61 , 표준편차가 1.3 으로 매우 낮았다. 5 개 문항 중 한 문항도 맞추지 못한 아 동이 $28 \%$ 나 되어 올바른 성지식에 대한 교육이 필요한 것으로 보인다. 다른 연구들(Lee 2004; Yoon 2004)에서도 초등학교 아동들의 성지식 수 준이 낮다고 보고하고 있었다. Park(2000)의 연구 에서는 성지식에 관한 문항 8 개의 평균점수가 100 점 만점에 46 점이라고 하여 본 연구대상자 들의 성지식 점수보다는 높았다. 이는 Park(2000) 의 연구에서는 매우 기초적인 것을 질문한데 비 해 본 연구에서는 난이도가 좀 더 높았기 때문으 로 사료된다. 그리고 본 연구대상자는 주로 초등 
학교 5 학년이었고 6 학년 아동에 비해 성교육 경험이 적었으므로 성지식 점수가 낮게 나온 것 으로 보인다.

성지식 점수에서 성별에 따른 차이가 발견되 었는데 여아가 남아보다 성지식 점수가 높았다 $(\mathrm{t}=-3.04, \mathrm{p}<.01)$. 여아가 성지식 정도가 높은 것은 $\operatorname{Park}(2000)$, Lee(2004), Yoon(2004)의 연구와 같은 결과였다. 남아가 여아에 비해 성에 대한 태도는 적극적이었으나 성에 대한 지식은 매우 단편적이 며 임신이나 피임, 성보건에 대한 것은 $70 \%$ 의 아 동들이 모르고 있다는 연구결과(Hwang 1999)는 특히 남아에게 올바른 성지식을 교육할 필요를 시사한다.

가정의 경제적 수준에 따른 차이는 나타나지 않았다. 저소득층 아동은 부모로부터 성지식을 얻기보다 학교 선생님이나 친구로부터 얻는 경우
가 일반아동에 비해 더 많았다. 그러므로 부모의 보호가 충분하지 않은 저소득층 아동이라 할지라 도 학교나 지역아동센터에서의 성교육을 통해 성 지식을 적절히 습득하고 있음을 알 수 있다.

성교육 경험 유무에 따른 차이는 뚜렷하였는 데 $(\mathrm{t}=-3.30, \mathrm{p}<.01)$ 성교육 경험이 있는 아동이 성 교육 경험이 없는 아동보다 성지식 점수가 높았 다. 이는 성교육이 아동의 올바른 성지식 습득과 관련이 됨을 말하며, 올바를 성지식 습득을 위해 성교육이 필요함을 시사한다.

\section{4. 성의식}

아동의 성에 대한 의식이 아동의 성과 가정의 경제적 수준, 그리고 성교육 경험 유무에 따라 차이가 있는가를 분석하여 그 결과를 Table 5에 제시하였다.

Table 5. Differences of sexual consciousness $(\mathrm{N}=425)$

\begin{tabular}{|c|c|c|c|c|c|}
\hline & & & $\mathrm{M}$ & SD & $\mathrm{t}$ \\
\hline \multirow{6}{*}{$\begin{array}{l}\text { Sex role } \\
\text { identity }\end{array}$} & \multirow{2}{*}{ Sex } & Boys & 3.18 & 1.92 & \multirow{2}{*}{-.70} \\
\hline & & Girls & 3.31 & 1.88 & \\
\hline & Economic & Middle & 3.29 & 1.99 & \multirow{2}{*}{.58} \\
\hline & background & Low & 3.17 & 1.69 & \\
\hline & \multirow{2}{*}{$\begin{array}{l}\text { Experience of } \\
\text { sex education }\end{array}$} & Yes & 3.26 & 1.87 & \multirow{2}{*}{-.19} \\
\hline & & No & 3.21 & 1.98 & \\
\hline \multirow{6}{*}{ Dating } & \multirow{2}{*}{ Sex } & Boys & 3.65 & 6.99 & \multirow{2}{*}{$2.08^{*}$} \\
\hline & & Girls & 2.60 & 2.22 & \\
\hline & Economic & Middle & 3.27 & 5.69 & \multirow{2}{*}{.90} \\
\hline & background & Low & 2.79 & 3.86 & \\
\hline & \multirow{2}{*}{$\begin{array}{l}\text { Experience of } \\
\text { sex education }\end{array}$} & Yes & 3.04 & 5.05 & \multirow{2}{*}{.50} \\
\hline & & No & 3.04 & 5.49 & \\
\hline \multirow{6}{*}{ Sex drive } & \multirow{2}{*}{ Sex } & Boys & 2.74 & 3.37 & \multirow{2}{*}{1.17} \\
\hline & & Girls & 2.38 & 2.76 & \\
\hline & Economic & Middle & 2.32 & 2.57 & \multirow{2}{*}{$-2.15^{*}$} \\
\hline & background & Low & 3.01 & 3.85 & \\
\hline & \multirow{2}{*}{$\begin{array}{l}\text { Experience of } \\
\text { sex education }\end{array}$} & Yes & 2.60 & 3.15 & \multirow{2}{*}{-.54} \\
\hline & & No & 2.40 & 2.83 & \\
\hline \multirow{6}{*}{ Sexual ethics } & \multirow{2}{*}{ Sex } & Boys & 3.14 & 1.87 & \multirow{2}{*}{-1.21} \\
\hline & & Girls & 3.51 & 3.55 & \\
\hline & Economic & Middle & 3.21 & 2.07 & \multirow{2}{*}{-1.01} \\
\hline & background & Low & 3.60 & 4.04 & \\
\hline & \multirow{2}{*}{$\begin{array}{l}\text { Experience of } \\
\text { sex education }\end{array}$} & Yes & 3.37 & 3.07 & \multirow{2}{*}{-.42} \\
\hline & & No & 3.21 & 2.12 & \\
\hline
\end{tabular}


Table 5에서와 같이 이성교제에는 성별에 따라 차이가 있었다 $(\mathrm{t}=2.08, \mathrm{p}<.05)$. 남아가 여아보다 이성교제에 개방적인 인식을 갖고 있었다. 이성 에게 관심을 갖는 것은 자연스러우며 이성 친구 를 사귀게 되면 부모님께 소개할 수 있다고 하는 개방적 태도가 남아에게서 더 높았다. 이는 여아 가 남아보다 이성교제에서 개방적인 태도를 보인 다는 선행연구들(Kwon 1999; Park 2000; Han 2002)과 다른 결과였다. 이성교제에 대한 태도에 서 가정의 경제적 수준이나 성교육 경험 유무에 따른 차이는 보이지 않았다.

성충동에는 경제적 수준 차이가 나타났다 $(\mathrm{t}=-2.15, \mathrm{p}<.05)$. 저소득 가정의 아동들이 성충동 이 경험하는 정도가 높은 것으로 나타났다. 이에 관한 선행연구들을 찾지 못하여 직접 비교는 어 려우나 본 연구의 이전 결과와 연결하여 논의하 면, 저소득 가정 아동들이 성지식을 부모로부터 얻기보다는 선생님으로부터 얻으며 성문제를 상 담할 사람을 뚜렷이 갖고 있지 못하므로 성충동 을 많이 경험하고 있는 것으로 이해된다. 일반아 동은 주로 부모로부터 성지식을 얻거나 성문제를 상담하는데 비해 저소득 가정 아동은 그 비율이 낮았다. 그러므로 저소득층 가정 아동들이 성충 동을 적절히 해소하지 못하고 있는 것으로 이해 된다.

성충동에서 아동의 성이나 성교육 경험 유무 에 따른 차이는 나타나지 않았다. Hwang(1999)은 초등학교 6학년 아동들을 조사하여 남아가 여아 보다 성충동을 많이 경험한다고 하였다. 본 연구 에서는 그러한 경향이 있었으나 의미있는 정도는
아니었다.

성역할정체감에서는 성차와 경제적 수준 차이 및 성교육 경험 유무 차이가 발견되지 않았다. 자신의 성에 만족하고 남녀의 성역할을 구분하는 고정관념에서 남아와 여아의 차이가 발견되지 않 았고 가정의 경제적 수준에 따른 차이도 나타나 지 않았다. 그러나 선행연구들(Hwang 1999; Han 2002)에서는 남아가 성역할을 구분하는 정도가 높고 양성평등에 대한 인식이 낮아 본 연구와 다 른 결과였다. 이는 학교나 사회에서 양성평등에 관해 꾸준히 교육하고 계몽한 결과로 오래 전의 연구와 달리 본 연구에서는 성역할정체감에서 성 차이가 나타나지 않은 것으로 사료된다. 최근에 이루어진 $\operatorname{Han}(2007)$ 의 연구에서도 성역할에 대해 남녀의 인식차이가 나타나지 않은 결과를 보여 아동의 성역할에 대한 인식은 점차 양성평등 방 향으로 변화되고 있음을 알 수 있다.

성윤리에 대한 인식에서도 성차와 경제적 수 준 차이가 나타나지 않았다. 이는 성윤리와 성태 도에서 아동의 성차가 나타나지 않았다고 보고한 Yoon(2004)과 Han(2007)의 연구결과와 같았다.

\section{5. 성지식과 성의식의 관계}

아동의 성지식과 성의식과의 관계를 알기 위 하여 Pearson의 적률상관 분석을 실시하였으며 그 결과는 Table 6과 같다.

Table 6에서와 같이 아동의 성충동은 성지식과 역상관 $(\mathrm{r}=-.12)$ 이 있으며 이성교제 $(\mathrm{r}=.16)$ 및 성윤 리와는 정상관 $(\mathrm{r}=.27)$ 이 있었다. 즉, 아동이 성충 동을 많이 경험하는 것은 성지식이 낮은 것과 상

Table 6 . Relations between sex knowledge and sexual consciousness

\begin{tabular}{|c|c|c|c|c|c|c|}
\hline & & \multirow{2}{*}{$\begin{array}{c}\text { Sex } \\
\text { knowledge }\end{array}$} & \multicolumn{4}{|c|}{ Sexual consciousness } \\
\hline & & & $\begin{array}{l}\text { Sex role } \\
\text { identity }\end{array}$ & Dating & $\begin{array}{l}\text { Sex } \\
\text { drive }\end{array}$ & $\begin{array}{l}\text { Sexual } \\
\text { ethics }\end{array}$ \\
\hline \multirow[t]{2}{*}{ Sex knowldege } & & 1.0 & & & & \\
\hline & Sex role identity & .06 & 1.0 & & & \\
\hline \multirow{3}{*}{$\begin{array}{l}\text { Sexual } \\
\text { consciousness }\end{array}$} & Dating & -.02 & -.02 & 1.0 & & \\
\hline & Sex drive & $-.12 *$ & .04 & $.16^{*}$ & 1.0 & \\
\hline & Sexual ethics & -.02 & -.02 & .04 & $.27 * *$ & 1.0 \\
\hline
\end{tabular}

$*_{\mathrm{p}}<.05, * * \mathrm{p}<.01$ 
관이 있었으며 이성교제에 대해 개방적으로 생각 하고 성윤리에 대해 엄격히 생각하는 것과 상관 이 있었다. 다시 말하면 성에 대해 올바른 지식 이 부족하고 이성교제에 대해 개방적인 태도를 가진 아동이 성충동을 많이 느낀다고 할 수 있으 며, 성충동이 높은 아동은 성윤리에 대해 보수적 이고 엄격한 인식을 갖고 있는 것으로 해석된다. 여기에서 흥미로운 점은 성충동을 많이 경험하는 아동이 높은 성윤리를 갖고 있다는 점이다. 이를 논의하면 성충동을 경험하면서 그것을 적절히 해 소하지 못하고 성충동을 경험하는 것을 나쁜 것 으로 인식하고 있을 가능성이 있다고 볼 수 있 다. 성충동을 많이 경험하는 아동들이 성윤리에 대한 것은 높이 인식하고 있어 높은 성윤리가 올 바른 성지식 부족과 함께 성충동을 경험하는 것 을 좋지 않게 인식할 수 있다는 우려를 낳는다. 그러므로 아동에게 올바른 성지식과 성윤리에 대 한 교육이 필요할 것이다. 본 연구에서는 이처럼 성지식과 성의식간에 상관이 있었으나 Yoon(2004) 의 연구에서는 거의 상관을 발견하지 못하였다.

\section{IV. 요약 및 결론}

본 연구는 경기도 $\mathrm{H}$ 시에 거주하는 초등학교 5,6 학년 아동들의 성교육 경험, 성학대 인식, 성지식 및 성의식에 대해 알아보고, 이들이 아동 의 성별과 가정의 경제적 수준에 따라 차이가 있 는가를 파악하고자 하였다. $\mathrm{H}$ 시는 도시와 농촌이 혼합된 도시이므로 지역에 따른 차이를 통제하고 자 도시와 농촌 지역에서 각각 한 개의 초등학교 에서 자료를 수집하였다. 또한 부모의 보호가 충 분하지 못한 가정의 아동들이 성문제에 노출될 가능성이 높으므로 지역아동센터를 이용하는 아 동들을 조사하였다. 저소득층 가정의 아동들이 지역아동센터를 주로 이용하므로 이들을 저소득 층으로 분류하여 가정의 경제적 수준에 따른 차 이를 분석하였다. 일반아동 자료는 초등학교에서, 저소득 가정 아동의 자료는 지역아동센터에서 자 료를 수집하였다.

연구 결과, 첫째로 성교육을 받은 경험이 없는 아동이 약 $1 / 4$ 이 되었다. 남아에 비해 여아는 가
정에서 성교육을 받았다고 응답한 아동이 많았으 며 성문제를 상담하는 대상도 부모님이라고 응답 한 여아가 남아보다 많았다. 남녀아 모두 성교육 이 성에 대한 올바른 지식 습득과 이성에 대한 바른 태도를 지니기 위해 필요한 것으로 보았으 나 남아는 성에 대한 호기심을 해소하기 위해서 라고 응답한 아동이 여아보다 많았다.

가정의 경제적 수준에 따른 차이도 나타났는 데 지역아동센터를 이용하는 저소득층 아동들이 성교육을 받은 경험이 더 많았고 성지식의 습득 도 가정보다는 학교와 지역아동센터 선생님을 통 해 얻는 경우가 많았다. 이를 보면 지역아동센터 를 이용하는 저소득 가정의 아동들에게 성에 대 한 정보와 지식을 전달하는 데 선생님의 역할이 중요한 것으로 보인다.

둘째, 아동이 성학대에 대해 어떻게 인식하고 있는지를 조사한 결과, 성학대는 가해자가 이상 한 사람이어서 일어난다고 응답한 경우가 $64.0 \%$ 로 가장 많았다. 그러나 자신이 어리고 약해보여 서라는 응답도 $25.4 \%$ 가 있어 성학대가 약한 대 상에게 가해지는 것으로 인식하고 있는 아동도 적지 않았다. 남아와 여아의 차이가 나타난 응답 도 있었는데 남아는 '가해자가 나를 좋아해서'라 는 응답이 여아보다 많은 반면 여아는 '내가 짧은 옷을 입어서'라는 응답이 남아보다 많았다. 이는 성학대에 자신의 잘못도 있다고 생각하는 경향이 남아보다 여아에게 더 높음을 의미한다.

셋째, 아동의 성에 대한 지식은 낮은 편이었 다. 5점 만점에 평균이 1.61 로 매우 낮았으며 5 개 문항 중 하나도 맞추지 못한 아동이 $28 \%$ 나 되어 올바른 성지식에 대한 교육이 필요한 것으로 보 인다. 특히 몽정과 자위행위에 대해 알고 있는 아동이 매우 적었다. 성지식 점수는 아동의 성에 따라 차이가 있었는데 여아의 성지식 점수가 남 아에 비해 높았다. 또한 성교육 경험 유무에 따 른 차이도 있었는데 성교육을 받은 경험이 있는 아동이 없는 아동에 비해 성지식 점수가 높았다. 이는 올바른 성지식 습득을 위해 성교육이 필요 함을 시사한다. 가정의 경제적 수준에 따른 아동 의 성지식 정도 차이는 발견되지 않았다.

넷째, 아동의 성의식 중 이성교제에 대한 의식 
에 성차가 발견되었다. 남아가 여아에 비해 개방 적인 이성교제 태도를 보이고 있었다. 아동의 성 충동에서는 저소득 가정 아동들이 성충동을 경험 하는 정도가 일반가정 아동들보다 높았다. 성역 할정체감과 성윤리에서는 성별에 따른 차이와 경 제적 수준에 따른 차이가 나타나지 않았다.

다섯째, 아동의 성지식과 성인식의 관계를 살 펴본 결과 아동의 성충동은 아동의 성지식이 낮 고 이성교제에 대해 개방적인 인식을 갖고 있으 며 성윤리가 높은 것과 상관이 있었다. 이러한 결과는 성지식이 왜곡되고 이성교제에 대해 개방 적인 의식을 갖고 있는 경우 성충동을 경험하는 것을 성윤리에 위배되는 것으로 인식할 수 있음 을 의미한다. 그러므로 아동에게 올바른 성지식 과 성윤리에 대한 교육이 필요할 것이다.

본 연구는 아동의 성교육 경험과 성학대에 대 한 인식, 성지식과 성에 대한 인식이 아동의 성 과 가정의 경제적 수준에 따라 어떠한 차이가 있 는가를 파악하고자 하였다. 연구 결과 성교육 경 험에서는 성차가 뚜렷하여 여아가 남아보다 가정 에서 부모로부터 성지식을 얻고 성문제를 상담하 고 있음을 알 수 있었다. 여아의 성지식이 높으 며 이성교제에 대해 남아보다 보수적인 태도를 보이고 있음을 알 수 있었다. 그리고 저소득층 아동들은 성지식을 가정 밖에서 주로 얻고 있었 고 성충동을 많이 경험하고 있었다. 성충동이 높 은 것은 높은 성윤리와 정상관이 있었으므로 성 충동을 적절히 해소하지 못할 경우 엄격한 성윤 리 기준으로 인해 불안을 경험할 우려가 있음을 알 수 있었다. 이러한 연구결과는 아동의 건전한 성을 위한 성교육을 계획하는 데 기초자료로 활 용될 수 있을 것이다.

이러한 발견에도 불구하고 본 연구는 몇몇 제 한점을 갖는데 가정의 경제적 수준 차이를 분석 하기 위하여 지역아동센터 이용 아동을 저소득층 으로 분류한 것이다. 초등학교를 대상으로 조사 한 일반 아동들 중에서도 저소득층에 속하는 아 동들이 있을 것이므로 본 연구에서 경제적 수준 에 따른 차이가 순수한 경제적 수준 차이가 못될 수 있다는 한계를 갖는다. 다음은 초등학교 5 학 년과 6학년을 조사하였으나 5 학년에 주로 치우쳐
학년 차이를 분석하지 못하였다는 점이다. 그리 고 성의식 측정도구의 신뢰도가 낮아 성의식을 적절히 측정하지 못했을 것이 우려된다. 선행연 구들에서 추출하여 신뢰도가 검증되었던 문항들 을 사용하였으나 본 연구에서 신뢰도가 낮았으므 로 아동의 성의식을 측정하는 도구의 개발이 필 요할 것으로 사료된다. 이러한 제한점이 있으나 본 연구 결과가 초등학교 고학년 아동들의 성에 대한 태도를 이해하고 그들을 위한 성교육 자료 를 구성하는 데 도움이 되는 자료가 되기를 희망 한다.

\section{References}

Ahn AS(1996) Children's perception of sexual abuse. Master's Thesis, Sookmyung Women's University

Choi ES(2004) Study on sex conscious and sexual harassment experience of primary school students. Master's Thesis, Chonnam National University

Choi YH, Kim YH, Sim MK, Sim HO(2009) Counseling for children. Changjisa: Seoul

Han EK(2002) Relationships between elementary school students knowledge about sex and attitude toward sex. Master's Thesis, Jeonju University

Han MS(2003) Study on the necessity and activating plans of the prevention of child maltreatment through participatory activity : around PAPCM operating case of the Goodneighbors Inchon branch. Master's Thesis, Sungsan Hyo University

Han HK(2007) Sexual consciousness of elementary school students and practice of sexual violence. Master's Thesis, Dongguk University

Hwang HJ(1999) A study on the sexual consciousness of elementary school children. Master's Thesis, Konkuk University

Jang MH(1998) The effect of sexual education program on the change of sexual knowledge and attitude of elementary school children. Master's Thesis, Korea University

Kang WJ(1994) A study on the development and effect of a sex education program on sound sex knowledge and the formation of the sex attitude of elementary school pupils. Master's Thesis, Pusan National University

Kim BS(2002) A study of current condition and improvement plan in sex education for upper grade elementary school students. Master's Thesis, Kongju National University

Kim HA(2002) The effect of a child sexual abuse prevention program in rural elementary school 
children. Master's Thesis, Yonsei University

Kim JK, Kim JS(2000) Psychological effects of childhood sexual abuse. Korean J Clin Psychol 19(4), 747-769

Kim JO(1998) The study on the present state and contents of school sexual education(II). J Soc Sci Res 5(3), 217-238

Kwak YJ(2011) The effect of poverty on the psychosocial adjustment of children: The mediating effects of child abuse and social capital within the family. Master's Thesis, Sookmyung Women's University

Kwon HS(2002) A study on the related variables upon sexual abuse female adolescent's resilience. Doctor's Thesis, Hongik University

Kwon YJ(1999) A study of sexual consciousness in senior students in primary school at Tae Jon. Master's Thesis, Chungnam University

Lee BJ, Kim KH(2007) Effects of family poverty and family structure on physical abuse and neglect of children. J Korean Counc Child Rights 11(3), 333-359

Lee MK(1996) The effects of sexual abuse prevention program on the children's perceptions of the risk of sexual abuse. Master's Thesis, Sookmyung Women's University

Lee JY, Kim JK(2006) The research regarding the psychological effects of the sexual abuse-Focusing on the sexual field-. Korean J Woman Psychol 11(4), 511-537
Lee YK(2004) Sex knowledge and sex attitude of elementary school. Master's Thesis, Myongji University

Ministry of Education(2008) Guidance for elementary school teacher: Right knowing about valuable sex.

Ministry of Health \& Welfare(2011) Report of national present of child abuse.

Minjungseorim(2008) Korean dictionary. Minjungseorim

Oh HS(2003) Study on group tratment program for female adult survivors of childhood sexual abuse. Doctor's Thesis, Ewha Women's University

Park $\mathrm{KO}(2000)$ A study on the sexual conscoiusness of elementary school children. Master's Thesis, Kyonggi University

Ryu MS, Ko KH, Park JW, Suh SD, Jeong CJ, Choi $\mathrm{KA}(2008)$ The effects of sex education program on adolescence sexual consciousness and sexual attitude. Forum Ment Health Policy 2, 140-161

Shin KS(2011) Sexually abused children's victimized experience. Korean J Psychol Gen 30(4), 12551287

Yoon KS(2004) A study on elementary school children's sexual perception and sex education. Master's Thesis, Mokpo University

Yoo SH(2006) The study on the sex attitude according to the sexual violence to elementary school students. Master's Thesis, Sungkyul University.

Youn MS, Kim SO(2001) The development of a healthy sexuality education program for early adolescent. J Korean Home Economics Assoc 39(5), 107-121 